Book reviews

\section{On defining death}

by Douglas $\mathrm{N}$ Walton. Montreal, McGill-Queen's University Press, I979, \$15.95.

In the muddy wake of the BBC TV Panorama programme on brain death and organ transplantation it has become apparent that there is confusion among doctors and the public alike about many practical, theoretical and moral issues related to the definition of death. In this context Walton's book On defining death is a welcome example of a sober and intelligently critical study of the basic issues involved.

He points out that the development of techniques for prolonged maintenance of ventilation, circulation, alimentation and excretion by artificial means, and the increasingly common use of procedures of organ transplantation, have raised two important kinds of moral questions:

a) when may death be said to occur, and

b) when is organ removal permissible.

On the one hand the rights of the potential donor are at stake, on the other hand the need of the potential recipient for 'live' (fresh) organs to replace damaged ones. These are questions which cannot be decided solely on medical grounds but 'our initial problem is to recognise that we are dealing with an interdisciplinary continuum of problems running from the concrete and practical all the way to the most abstract and theoretical'.

Implied in his two basic questions are a whole cluster of other questions which he shows require careful philosophical analysis: what does it mean to define death? What are appropriate criteria for the determination of death ? Is a consistently secular view of death possible? Are concepts of resurrection and immortality relevant to the way we think about death ? Is the distinction between active and passive eutha- nasia a coherent one? Is voluntary euthanasia a form of indirect action? Is allowing nature to have its course different from bringing about someone's death? Is it rational to fear death ?

These are fascinating questions and are handled by Walton in an illuminating and helpful wayfor those capable of following the highly sophisticated philosophical argument of the book! His interests are clearly those of a philosopher and a specialist in philosophical logic. Although the book is written with admirable clarity and never loses sight of the important central questions, a basic knowledge of the philosophical problems associated with definition, counterfactual conditionals, the verification debate, theories of casuality, Anselmian semantics, negation and modern theories of action are necessary to appreciate the niceties of the argument.

Fortunately some parts of the book are more accessible to the nonphilosopher than others. There is a detailed and well-informed discussion of the traditional and new criteria for defining death. This includes comparative discussion of the Harvard criteria, European requirements for determining cerebral blood circulation, and the multiple criteria suggested by the Conference of Medical Royal Colleges. The role and limitations of the electroencephalograph and angiography are also examined.

He points out some apparent difficulties for a thorough-going secular view of death; thus is it meaningful to refer to death as an experience; who is it that is said to be dead; and is it not irrational to fear death if death is the cessation of consciousness? In a somewhat laboured argument he advances 'the superlimiting theory of death' to defend the consistency of talk about death from a secular point of view. His solution amounts to saying that when the secularist refers for example to death as not unfortunate he is referring to the possible benefits which might accrue to a possibtre person were he to survive death This argument, like his distinction between death as experience and $\overrightarrow{2 s}$ projection, is based on a theoretica analysis of counterfactual cor ditionals in order to clarify the distinction between actual and possible experience.

In discussing the religious coter ception of death he distinguishes between the (Greek) doctrine of the immortal soul and the (JudeoChristian) doctrine of the resun rection of the body. He gives sympathetic account of the theory of eschatological verification wheretg Hick attempts to rebut Flew's criticism that statements abou $\overrightarrow{0}$ resurrection are unverifiable poñ $^{\circ}$ sense. Hick argues that the hipgthesis of the resurrection of the is verifiable but not falsifiab not falsifiable because if false then nobody will ever know that it is falso, but verifiable in principle because is not impossible that someone could survive death and know it be true. This rather sophistical argument, he points out, soun somewhat circular, but the secular rebuttal of it does as well! O花 amusing consequence of his arg ment is that it may be more rationg to fear death if you are a Christian than if you are an atheist, for in the first case you may rightly fear some thing after death but in the lattor case there is literally nothing to fear.

Although the sections of the bo dealing with active and passize euthanasia, killing and letting difo acts and omissions, are the most technical and difficult to follow they are ultimately the most useful and illuminating. By careful attention to the logic governing distinctions such as that between active and passive euthanasia, demonstrates most convincingly that the minimal syntax of the distinction is clear and precise. While the practical dilemmas faced by doctors may be made no easier by logigl analysis, the distinction is ngt 
unclear in principle, and this is reassuring.

In the face of criticisms from Rachels and others who suggest that, judged in terms of consequences, there is no significant distinction between killing and letting die, Walton produces a powerful argument, based on Anselmian semantics, to demonstrate the coherence of the distinction between making happen and letting happen as two different kinds of intentional act. This is welcome reinforcement for the intuitive conviction of many doctors that there is a valid distinction to be drawn here, and their resistance to the argument that would drive further towards the justification of medically initiated euthanasia. It is perhaps less obvious that the detailed arguments based on distinctions in the philosophy of action help to clarify the specifically moral issues in the debate about voluntary euthanasia.

This is an impressive book and will probably become a standard philosophical work on the subject. It merits careful study and more detailed criticism than that attempted here. Required reading for philosophers interested in thanatology, it can also be recommended to the doctor with the time to do some serious critical refection on the philosophical basis of his ethics and action.

IAN E THOMPSON

Scottish Health Education Group Edinburgh

\section{Clinical Trials}

by Daniel Schwartz, Robert Flamant and Joseph Lellouch, translated by M J R Healy, Academic Press, I980, 28I pp. $£ 15.00$ or $\$ 34.50$.

This book was originally published in 1970, and as the r980 edition has only 'minor changes' it can inevitably be criticised for not being adequately updated. The authors discuss almost exclusively comparative clinical trials using concurrent controls. There are two pages on 'non-comparative' trials, ie without concurrent controls, but there is no adequate discussion of the important topic of retrospective controls, though there is an expression of general disapproval. Where retrospective controls are scientifically acceptable it is not appropriate to describe the trial as 'noncomparative'.
But the main thrust of the book is to tell us that there are two kinds of comparative clinical trial, the explanatory and the pragmatic. We are told that 'the crucial point is to decide which category a trial falls into, and, if the trial is of the ambiguous variety, which of the two approaches should be preferred'. Unfortunately the distinction between these in the context of the randomised controlled trial, does not hold. We are given to understand that the 'explanatory' trial is one where the gaining of scientific knowledge is the principal aim and the 'pragmatic' trial is ' $a$ sort of dress rehearsal for practices which will be eventually adopted'. But this distinction is not maintained since 'evaluating the cure rate is essentially an explanatory activity', though one might have thought it the essence of a 'pragmatic 'trial as defined here.

The authors confuse the stages of development of a new treatment (p4), and put into their stage (III), the controlled comparative trial, much of the work that would have been done earlier (stage II), eg comparative randomised controlled designs are not used to ascertain whether a drug 'actually possesses the favourable activity in man which laboratory studies have led us to expect'. Constantly the reader finds minor distinctions inflated to major differences of principle, eg an 'explanatory' trial is 'concerned essentially with the course of the disease and expressed ... in strictly defined biological terms' and a 'pragmatic' trial 'may (!) also be concerned with the course of the disease in an overall way. ... These are typical quotations; detailed reading of the book further compounds confusion.

In their summing up the authors seem finally to admit the unreality of their distinction applied to comparative trials, though of course, to research in general, the distinction between 'non-therapeutic' (where the subject can expect no personal benefit) and 'therapeutic' (where the subject may obtain personal benefit) is valuable and familiar.

This brings me to the ethics of clinical trials, a subject which has received so much attention in recent years. At the end of Chapter I the authors state 'we shall put off a full discussion of the ethical problem until near the end of the book'. A chapter is given to the topic. The authors envisage a doctor who is 'confident' that a new treatment is better than the standard one engaging in a trial. 'If the trial confirms the settled opinion of the doctors who are in favour of the new treatment, the burden of experimentation may seem heavy to them and they may feel that they have been asked to sacrifice some of their patients to the demands of scientific rigour' (reviewer's italics).

The widely and correctly held view that a doctor who is confident that a treatment is best cannot ethically join in a trial that may sacrifice his patients is not considered, nor what such a doctor would say to his patients, nor how their consent to receive a treatment confidently judged to be inferior would be obtained, that is, if it could be obtained! The whole crucial issue of consent is ignored.

To sum up, this is a book on which those with knowledge and experience of clinical trials may wish to sharpen their wits, but it cannot be recommended to anyone seeking a straightforward account of the subject. The ethical discussion is inadequate.

D R LAURENCE University College Hospital Medical School? London

\section{Conquering Cancer}

by Lucien Israel. Translated from the French by Joan Pinkham. Penguin Books, 1980, 269 pp. £2.25.

It is no cause for surprise that $\mathrm{Dr}$ Israel fails to make good the claim when he promises in the preface of this book to 'present all the information on cancer that is readily available, but that . . . had not yet been gathered between covers'. It, after all, could scarcely be compressed into a 269 page paperback. Indeed the amount of factual information Conquering Cancer contains is scanty and limited to general statements about the nature and natural history of cancer.

The greater part of the book concerns itself with treatment. Many medical oncologists will find themselves in sympathy with $\mathrm{Dr}$ Israel's approach. He points out that 80 per cent of those dying of cancer die from the effects of metastases and only 20 per cent as a direct result of the primary tumour. He believes that dissemination always occurs early in the course of any cancer, but that the body's immunological 